\title{
Health Behaviour and Self-reported Academic Performance among University Students: An International Study
}

\author{
Karl Peltzer \\ ASEAN Institute for Health Development, Madidol University, Salaya, Phutthamonthon, Nakhonpathom, Thailand, 73170, \\ University of Limpopo, Turfloop Campus, Sovenga 0727, South Africa, HIV/AIDS/STIs/and TB (HAST), \\ Human Sciences Research Council, Private Bag X41, Pretoria 0001, South Africa \\ Supa Pengpid \\ ASEAN Institute for Health Development, Madidol University, Salaya, Phutthamonthon, Nakhonpathom, \\ Thailand, 73170, University of Limpopo, Turfloop Campus, Sovenga 0727, South Africa \\ Email: supaprom@yahoo.com
}

\section{Doi:10.5901/mjss.2014.v5n27p998}

\section{Abstract}

The aim of this study was to investigate health correlates of academic performance among university students from 26 low and middle income and emerging economy countries. Using anonymous questionnaires, data were collected from 20222 university students, $41.5 \%$ men and 58.5\% women, with a mean age of 20.8 years (SD=2.8), from 26 countries across Africa, Asia and Americas. Overall, $28.4 \%$ reported excellent or very good, $65.5 \%$ good or satisfactory and $6.2 \%$ not satisfactory academic performance. Multivariate linear regression found that that sociodemographic factors (younger age, coming from a wealthier family background, lack of social support and high intrinsic religiosity), health behaviours (trying to eat fibre, avoiding fat and cholesterol, high levels of physical activity, no illicit drug use, not drinking and driving), and better mental health (no severe sleep problem and no moderate or severe depression) were associated self-reported academic performance. Several clustering health behaviours were identified which can be utilized in public health interventions.

Keywords: Academic performance; Correlates; University students; Multi-country

\section{Introduction}

High academic performance of university students can be important for a better career success (Bretz Jr, 1989; Deliens, Clarys, De Bourdeaudhuij \& Deforche, 2013). Different sociodemographic factors have been found to be associated with academic performance. These include female gender (Vaez \& Laflamme, 2008), older age (El Ansari \& Stock, 2010), higher socioeconomic status (Sirin 2005), religious involvement (Trockel, Barnes, \& Egget, 2000; Walker \& Dixon, 2002) and social support (Malecki \& Demaray, 2006).

Various specific health behaviours have also been found to be associated with academic performance (Cogollo \& Gómez-Bustamante, 2013). These include healthy dietary behaviours (Bradley \& Greene, 2013), good diet quality (Florence, Asbridge \& Veugelers, 2008), adequate fruit and vegetable intake (Wald, Muennig, O'Connell \& Garber, 2014), not being on a diet (Deliens et al., 2013), moderate-vigorous physical activity (Bradley \& Greene, 2013; Wald et al., 2014), no or infrequent alcohol use (Aertgeerts \& Buntinx, 2002; Bradley \& Greene, 2013; Deliens et al., 2013); no tobacco use (Bradley \& Greene, 2013), no other drug use (Bradley \& Greene, 2013), no violent behaviour (Bradley \& Greene, 2013), adequate sleep duration (Wald et al., 2014), good sleep quality (Gomes, Tavares \& de Azevedo, 2011), earlier bedtimes and wake times (Eliasson, Lettieri \& Eliasson, 2010; Trockel et al., 2000), and less risky sexual behaviour such as consistent condom use (Bradley \& Greene, 2013; Mehra, Kyagaba, Ostergren \& Agardh, 2014).

The aim of this study was to investigate health correlates of academic performance among university students from 26 low and middle income and emerging economy countries. 


\section{Methods}

\subsection{Participants and procedures}

This cross-sectional study was carried out with a network of collaborators in participating countries (see Acknowledgments). The anonymous, self-administered questionnaire used for data collection was developed in English, then translated and back-translated into languages (Arabic, Bahasa, French, Lao, Russian, Spanish, Thai, Turkish) of the participating countries. The study was initiated through personal academic contacts of the principal investigators. These collaborators arranged for data to be collected from intended 400 male and 400 female undergraduate university students aged 16-30 years by trained research assistants in 2013 in one or two universities in their respective countries. The universities involved were located in the capital cities or other major cities in the participating countries. Research assistants working in the participating universities asked classes of undergraduate students to complete the questionnaire at the end of a teaching class. Classes were recruited according to timetable scheduling using stratified random sampling. The students who completed the survey varied in the number of years for which they had attended the university. A variety of majors were involved, including education, humanities and arts, social sciences, business and law, science, engineering, manufacturing and construction, agriculture, health and welfare and services. Informed consent was obtained from participating students, and the study was conducted in 2013. Participation rates were in most countries over 90\%. Ethics approvals were obtained from institutional review boards from all participating institutions. Countries included in the study were: Bangladesh ( $n=800)$, Barbados $(n=580)$, Cameroon $(n=627)$, China (1184), Colombia ( $n=816)$, Egypt $(n=831)$, Grenada $(n=435)$, India (800), Indonesia $(n=750)$, Ivory Coast $(n=824)$, Jamaica $(n=762)$, Kyrgyzstan $(n=837)$, Laos $(n=806)$, Madagascar $(n=800)$, Mauritius $(n=501)$, Namibia $(n=503)$, Nigeria $(n=820)$, Pakistan ( $n=813)$, Philippines ( $n=968)$, Russia $(n=799)$, Singapore $(n=894)$, South Africa $(n=888)$, Thailand $(n=860)$, Tunisia ( $n=960)$, Turkey $(n=800)$, Venezuela $(n=564)$.

\subsection{Measures}

Academic performance. Academic performance was assessed with the question, 'how would you rate your academic performance?' Response options ranged from 1=excellent to 5=not satisfactory.

Socio-demographic questions included age, gender, and socioeconomic background were assessed by rating their family background as wealthy (within the highest $25 \%$ in "country", in terms of wealth), quite well off (within the $50 \%$ to $75 \%$ range for their country), not very well off (within the $25 \%$ to $50 \%$ range from "country"), or quite poor (within the lowest $25 \%$ in their country, in terms of wealth) (Wardle \& Steptoe, 1991). We subsequently divided the students into poorer (not very well off and quite poor) and wealthier (wealthy, quite well off) categories.

Social support. Three items were drawn from the Social Support Questionnaire to assess perceived social support (Brock, Sarason, Sarason \& Pierce, 1996). The items were selected to reflect perceived tangible and emotional support, e.g.,"If I were sick and needed someone to take me to a doctor I would have trouble finding someone." These items were responded to on 4-point scales, $1=$ completely true, to $4=$ completely false, and summed to a score with a range of 3-12. Cronbach's alpha for this sample was 0.95 .

Religiousness was assessed with the 3 item intrinsic (or subjective) religiosity sub-scale of Duke University Religion Index (DUREL; Koenig, Parkerson \& Meador, 1997). Cronbach's alpha for the intrinsic religiosity sub-scale was .96 for this sample.

\subsection{Health behaviour:}

Fruit and vegetable consumption was assessed with two questions, "How many servings of fruit do you eat on a typical day?" and "How many servings of vegetables do you eat on a typical day?" using the 24-h dietary recall data as the gold standard (Hall, Moore, Harper \& Lynch, 2009). Cronbach alpha for this fruit and vegetable measure was 0.74 . Sufficient fruit and vegetable consumption was defined as less than five servings of fruits and/or vegetables a day (Hall et al., 2009). Additional dietary variables included: (a) trying to avoid eating foods that contain fat and cholesterol (yes, no); (b) trying to eat foods that are high in fibre (yes, no); (c) frequency of having breakfast (Wardle \& Steptoe, 1991).

Physical activity was assessed using the self-administered International Physical Activity Questionnaire (IPAQ) short version, for the last 7 days (IPAQ-S7S). We used the instructions given in the IPAQ manual for reliability and validity, which is detailed elsewhere (Craig et al., 2003. We categorized physical activity (short form) according to the official IPAQ scoring protocol (International Physical Activity Questionnaire, 2014) as low, moderate and high. 
Tobacco use was assessed with the question: Do you currently use one or more of the following tobacco products (cigarettes, snuff, chewing tobacco, cigars, etc.)? Response options were "yes" or "no" (WHO, 1998).

Binge drinking was assessed with one item, "How often do you have (for men) five or more and (for women) four or more drinks on one occasion?" Response options ranged from 1=never to 5=daily or almost daily (Babor, Higgins-Biddle, Saunders \& Monteiro, 2001).

Illicit drug use was assessed with the question, "How often have you taken drugs in the past 12 months; other than prescribed by the health care provider."

Physical fight. For the main outcome, study participants were asked, "During the past 12 months, how many times were you in a physical fight?" Response options ranged from "0 times" to "12 or more times". (CDC, 2013).

Seat belt use was assessed with the question, "When driving or riding in the front seat of a car do you wear a seat belt?" Response options were, All the time, Some of the time, Never, I don't ride in cars (Wardle \& Steptoe, 1991).

Drinking and driving. Participants were asked, "Over the last year, how many times did you drive a car or ride a motorcycle when you felt that you had perhaps had too much to drink? Response options were "never", or a numerical indication of the number of times.

Sexual risk behaviour was assessed with the consistency of condom use in the past three months.

\subsection{Sleep and mental health}

Sleep duration. Students were asked, "On average, how many hours of sleep do you get in a 24 hour period?"(Steptoe, Peacey \& Wardle, 2006). Responses were divided into three categories: short sleep ( $\leq 6$ hours), reference category (7-8 hours), and long sleep ( $\geq 9$ hours) (Hublin, Partinen, Koskenvuo \& Kaprio, 2007; Steptoe et al., 2006).

Sleep problems were estimated based on the question: 'Overall in the last 30 days, how much of a problem did you have with sleeping, such as falling asleep, waking up frequently during the night, or waking up too early in the morning?' Response options ranged from 1 (none) to 5 (extreme/cannot do). Sleep problems were defined by the response to this question with 'severe' or 'extreme/cannot do' (Stranges, Tigbe, Gómez-Olivé, Thorogood \& Kandala, 2012).

Centers for Epidemiologic Studies Depression Scale (CES-D). We assessed depressive symptoms using the 10item version of the CES-D (Andresen, Malmgren, Carter \& Patrick, 1994). Scoring is classified from 0-9 as having a mild level of depressive symptoms, 10 to 14 as moderate depressive symptoms, and $\geq 15$ representing severe depressive symptoms (Kilbourne et al., 2002). The Cronbach a reliability coefficient of this 10 -item scale was 0.78 in this study.

Post traumatic stress disorder (PTSD). Breslau's 7-item screener was used to identify PTSD symptoms in the past month (Kimerling et al., 2006). Items asked whether the respondent had experienced difficulties related to a traumatic experience (e.g., "Did you begin to feel more isolated and distant from other people?"). The Cronbach alpha reliability coefficient of this 7 -item scale was 0.75 in this study.

\section{Data Analysis}

Data analysis was performed using STATA software version 11.0 (Stata Corporation, College Station, Texas, USA). Descriptive statistics were used for reporting the proportion of academic performance and Pearson Chi-square for gender differences in proportion of academic performance fighting. Linear regression was used to assess the association between sociodemographic variables, health behaviour, sleep and mental health and academic performance. Variance inflation factor (VIF) and tolerance values for each model indicate multicollinearity was not a concern in any of the multivariate analyses. Since the study used a clustered design, country was included as a clustering variable in the regression models.

\section{Results}

\subsection{Sample characteristics}

The sample included 20222 university students, $41.5 \%$ men and $58.5 \%$ women, with a mean age of 20.8 years (SD=2.8), from 26 countries across Africa, Asia and Americas. Overall, $28.4 \%$ reported excellent or very good, $65.5 \%$ good or satisfactory and $6.2 \%$ not satisfactory academic performance. Table 1 describes the academic performance of the university students in relation to sociodemographic, health behaviour and sleep and mental health variables (see Table 1). 
Table 1: Sample characteristics and academic performance

\begin{tabular}{|c|c|c|c|c|}
\hline & \multicolumn{3}{|c|}{ Academic performance } & \multirow{2}{*}{\begin{tabular}{|c|}
$\mathbf{X}^{2}$ \\
-value
\end{tabular}} \\
\hline Variables & Excellent or very good & Good or satisfactory & Not satisfactory & \\
\hline \multicolumn{5}{|l|}{ Sociodemographics } \\
\hline $\begin{array}{c}\text { All } \\
\text { Age in years } \\
16-19 \\
20-21 \\
22-30\end{array}$ & $\begin{array}{l}28.4 \\
38.7 \\
34.8 \\
26.5\end{array}$ & $\begin{array}{l}65.5 \\
32.3 \\
36.0 \\
31.7\end{array}$ & $\begin{array}{c}6.2 \\
32.8 \\
35.8 \\
31.4\end{array}$ & $<0.001$ \\
\hline $\begin{array}{l}\text { Gender } \\
\text { Female }\end{array}$ & 59.2 & 59.0 & 49.1 & $<0.001$ \\
\hline $\begin{array}{c}\text { Family economic background } \\
\text { Quite poor/not very well off } \\
\text { Wealthy/quite well-off }\end{array}$ & $\begin{array}{l}37.6 \\
62.4\end{array}$ & $\begin{array}{l}49.0 \\
51.0\end{array}$ & $\begin{array}{l}56.1 \\
43.9 \\
\end{array}$ & $<0.001$ \\
\hline Social support (high) & 46.8 & 40.8 & 35.2 & $<0.001$ \\
\hline $\begin{array}{c}\text { Intrinsic religiosity } \\
\text { Low } \\
\text { Medium } \\
\text { High }\end{array}$ & $\begin{array}{l}28.3 \\
38.1 \\
33.6\end{array}$ & $\begin{array}{l}34.9 \\
35.1 \\
30.0\end{array}$ & $\begin{array}{l}42.3 \\
30.4 \\
27.3 \\
\end{array}$ & $<0.001$ \\
\hline \multicolumn{5}{|l|}{ Health behaviour } \\
\hline Fruit and vegetables ( 5 or more servings/day) & 19.4 & 19.1 & 17.7 & 0.461 \\
\hline Trying to eat fibre & 43.2 & 38.4 & 36.7 & $<0.001$ \\
\hline Avoiding fat and cholesterol & 40.3 & 38.6 & 37.1 & 0.041 \\
\hline Skip breakfast & 44.4 & 46.6 & 49.7 & $<0.001$ \\
\hline Physical activity (high) & 33.3 & 31.3 & 28.5 & $<0.001$ \\
\hline Current tobacco use & 12.1 & 13.0 & 16.2 & $<0.001$ \\
\hline Binge drinking (at least once/month) & 12.1 & 12.0 & 12.8 & 0.673 \\
\hline Illicit drug use (past year) & 15.5 & 19.9 & 25.3 & $<0.001$ \\
\hline Physical fighting (past year) & 13.2 & 13.0 & 13.6 & $<0.001$ \\
\hline Always using seatbelt & 49.2 & 44.3 & 40.5 & $<0.001$ \\
\hline Drinking and driving (past year) & 25.2 & 26.9 & 38.8 & $<0.001$ \\
\hline Consistent condom use & 21.8 & 23.0 & 20.8 & 0.200 \\
\hline \multicolumn{5}{|l|}{ Sleep and mental health } \\
\hline $\begin{array}{c}\text { Sleep duration } \\
7-8 \text { hours } \\
6 \text { or less } \\
9 \text { or more } \\
\end{array}$ & $\begin{array}{l}47.5 \\
39.0 \\
13.4 \\
\end{array}$ & $\begin{array}{l}46.3 \\
39.4 \\
14.3 \\
\end{array}$ & $\begin{array}{l}43.6 \\
41.6 \\
14.8 \\
\end{array}$ & 0.122 \\
\hline Sleep problem & 9.6 & 10.2 & 15.5 & $<0.001$ \\
\hline Depression symptoms (moderate to severe) & 31.2 & 38.4 & 55.7 & $<0.001$ \\
\hline PTSD symptoms & 20.2 & 20.4 & 30.4 & $<0.001$ \\
\hline
\end{tabular}

\subsection{Associations with academic performance}

In multivariate linear regression, it was found that sociodemographic factors (younger age, coming from a wealthier family background, lack of social support and high intrinsic religiosity), health behaviours (trying to eat fibre, avoiding fat and cholesterol, high levels of physical activity, no illicit drug use, not drinking and driving), and better mental health (no severe sleep problem and no moderate or severe depression) were found to be associated self-reported academic performance (see Table 2). 
Table 2: Linear regression analysis for association between independent variables and self-reported academic performance

\begin{tabular}{|c|c|c|c|c|}
\hline & \multicolumn{2}{|c|}{ Univariate } & \multicolumn{2}{|c|}{ Multivariate } \\
\hline Variables (\%) & $\mathrm{t}$ & $\beta$ & $\mathrm{t}$ & $\beta$ \\
\hline \multicolumn{5}{|l|}{ Sociodemographics } \\
\hline \multicolumn{5}{|l|}{ Age in years } \\
\hline $16-19$ & Ref. & & Ref. & \\
\hline $20-21$ & $-5.10^{* \star *}$ & -0.043 & $-5.66^{* \star *}$ & -0.073 \\
\hline $22-30$ & $-9.21^{* * *}$ & -0.077 & & -0.044 \\
\hline \multicolumn{5}{|l|}{ Gender } \\
\hline Male (base=Female) & $-3.42^{\star \star \star}$ & -0.024 & -0.64 & -0.008 \\
\hline \multicolumn{5}{|l|}{ Family economic background } \\
\hline $\begin{array}{l}\text { Quite poor/not very well off } \\
\text { Wealthy/quite well-off }\end{array}$ & $\begin{array}{l}\text { Ref. } \\
22.26^{\star \star \star}\end{array}$ & 0.158 & $\begin{array}{l}\text { Ref. } \\
12.80^{\star \star \star}\end{array}$ & 0.152 \\
\hline Social support (high) (base=low) & $-10.17^{\star \star \star}$ & $\begin{array}{l}0.100 \\
-0.079\end{array}$ & $-5.87^{\star \star \star}$ & -0.067 \\
\hline \multicolumn{5}{|l|}{ Intrinsic religiosity } \\
\hline Low & Ref. & & Ref. & \\
\hline Medium & $10.63^{\star \star \star}$ & 0.087 & $5.90^{\star \star \star}$ & 0.078 \\
\hline High & $12.82^{\star \star \star}$ & 0.105 & $6.33^{* \star *}$ & 0.085 \\
\hline \multicolumn{5}{|l|}{ Health behaviour } \\
\hline Fruit and vegetables (5 or more servings/day) & 1.71 & 0.013 & 0.16 & 0.002 \\
\hline Trying to eat fibre & $5.46^{\star \star \star}$ & 0.040 & 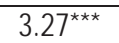 & 0.040 \\
\hline Avoiding fat and cholesterol & $3.56^{\star \star \star}$ & 0.026 & $2.14^{\star}$ & 0.026 \\
\hline Skip breakfast & $-5.29^{\star \star \star}$ & -0.038 & -1.63 & -0.019 \\
\hline Physical activity: High (base=low or medium & $5.63^{\star \star \star}$ & 0.040 & $3.60^{\star \star \star}$ & 0.041 \\
\hline Current tobacco use (base=none) & $-2.01^{*}$ & -0.015 & -1.57 & -0.019 \\
\hline Binge drinking (at least once/month) & 0.26 & 0.002 & -.- & \\
\hline Illicit drug use (past year) & $-10.43^{\star \star \star}$ & -0.081 & $-2.85^{\star \star}$ & -0.033 \\
\hline Physical fighting & 1.30 & 0.010 & --- & \\
\hline Always using seatbelt & $6.99 * \star \star$ & 0.054 & 1.41 & 0.017 \\
\hline Drinking and driving & $-7.65^{\star \star \star}$ & -0.065 & $-5.71^{\star \star \star}$ & -0.069 \\
\hline Consistent condom use & -1.27 & -0.012 & --- & \\
\hline \multicolumn{5}{|l|}{ Sleep and mental health } \\
\hline \multicolumn{5}{|l|}{ Sleep duration } \\
\hline 7-8 hours & Ref. & & Ref. & \\
\hline 6 or less & -1.59 & -0.012 & -1.77 & -0.021 \\
\hline 9 or more & $-2.41^{*}$ & -0.019 & -0.21 & -0.002 \\
\hline Sleep problem & $-5.51^{\star \star *}$ & -0.040 & $-3.99 * \star \star$ & -0.046 \\
\hline Depression symptoms (moderate to severe) & $-14.45^{\star \star \star}$ & -0.103 & $-4.72^{\star \star \star}$ & -0.056 \\
\hline PTSD symptoms & $-5.26^{* \star \star}$ & -0.039 & $-2.02^{\star}$ & -0.024 \\
\hline
\end{tabular}

\section{Discussion}

The purpose of the study was to investigate differences in sociodemographics, health behaviour, sleep and mental health and self-reported academic performance in a large sample of university students from 26 countries. Results indicate in agreement with previous studies (Sirin, 2005; Malecki \& Demaray, 2006; Trockel et al., 2000; Walker \& Dixon, 2002) that sociodemographic factors (coming from a wealthier family background, social support and high intrinsic religiosity) were associated with academic performance. Coming from a poorer family background may put financial pressures on students and affect their academic performance negatively (El Ansari \& Stock, 2010). Economic factors of academic outcomes may need to be addressed with scholarship and/or financial support programmes (El Ansari \& Stock, 2010). Other studies (Richardson, Abraham \& Bond, 2012) also showed the positive association between social support, academic intrinsic motivation and academic performance.

Further, the study found that certain healthy dietary behaviours (trying to eat fibre, avoiding fat and cholesterol) were associated with better academic performance. This finding has been confirmed by some other research (Bradley \& Greene, 2013; Florence et al. 2008). Contrary to a study by Wald et al. (2014), this study did not find an associated 
between adequate fruit and vegetable intake and academic performance. Students with high levels of physical activity were more likely to have better academic performance, which is conform with previous studies (Bradley \& Greene, 2013; Singh, Uijtdewilligen, Twisk, van Mechelen \& Chinapaw, 2012; Wald et al., 2014). Various studies have shown the generally positive impact of physical activity on student's cognitive and psychosocial function (Lees \& Hopkins, 2013).

Regarding substance use, the study found that illicit drug use and drinking and driving and in univariate analysis tobacco use were associated with lower academic performance. These results are in line with previous findings (Bradley \& Greene, 2013). Unlike some previous studies (Aertgeerts \& Buntinx, 2002; Bradley \& Greene, 2013; Deliens et al., 2013), this study did not find an association between alcohol use (binge drinking) and academic performance.

Although this study did not find an associated between adequate sleep duration and academic performance, in bivariate analysis long sleep duration and skipping breakfast were inversely related to academic performance. It is possible that students who engage in long sleep duration are more likely to skip breakfast in order to attend classes. Trockel et al. (200) also found that late wake-up times were associated with poorer academic performance in US university students, and Gajre, Fernandez, Balakrishna and Vazir (2008) found among Indian students that regular eating breakfast was associated with better cognitive functioning.

Students indicating that they had a sleep problem were much more likely to have poor academic performance than those who did not have a sleep problem. This finding that good sleep quality is associated with better academic performance has been found previously (Gomes et al., 2011). Similarly, depressive symptoms were more likely in students with poorer than good or excellent self-rated academic performance. Mental health complaints may reduce the students' capacity to perform academically at the university (El Ansari \& Stock, 2010; Keyes, Eisenberg, Perry, Dube, Kroenke \& Dhingra, 2012; Turner, Thompson, Huber \& Arif, 2012). On the other hand, it is also possible that poor academic performance may lead to depressive symptoms and/or sleep problems. However, since this is a cross-sectional study the direction of the association cannot be established. Nevertheless, this finding indicates the importance of identifying and preventing of depressive symptoms and sleep problems through university health programmes (El Ansari \& Stock, 2010).

\section{Limitations of the Study}

This study had several limitations. The study was cross-sectional, so causal conclusions cannot be drawn. The investigation was carried out with students from one or two universities in each country, and inclusion of other centres could have resulted in different results. A further limitation of the study was that all information collected in the study was based on self-reporting, including the measure of academic performance. It is possible that certain behaviours were under or over reported. Academic performance should in future studies also be assessed with actual Grade Point Averages (GPA), as has been done in a number of studies (e.g., Deliens et al., 2012).

\section{Conclusion}

The study found, among a large sample of university students from 26 low, middle income and emerging economy countries across Asia, Africa and the Americas, a significant proportion of not satisfactory academic performance. Various health risk factors including dietary, physical inactivity, substance use, sleep problem, and depression symptoms were identified which may be utilized in interventions aiming at the promotion of academic performance among university students.

\section{Acknowledgements}

Partial funding for this study was provided by the South African Department of Higher Education. The following colleagues participated in this student health survey and contributed to data collection (locations of universities in parentheses) Bangladesh: Gias Uddin Ahsan (Dhaka); Barbados: T. Alafia Samuels (Bridgetown); Cameroon: Jacques Philippe Tsala Tsala (Yaounde); China: Tony Yung and Xiaoyan Xu (Hong Kong and Chengdu); Colombia: Carolina Mantilla (Pamplona); Egypt: Alaa Abou-Zeid (Cairo); Grenada: Omowale Amuleru-Marshall (St. George); India: Krishna Mohan (Visakhapatnam); Indonesia: Indri Hapsari Susilowati (Jakarta); Ivory Coast: Issaka Tiembre (Abidjan); Jamaica: Caryl James (Kingston); Kyrgyzstan: Erkin M Mirrakhimov (Bishkek); Laos: Vanphanom Sychareun (Vientiane); Madagascar: Onya H Rahamefy (Antananarivo); Mauritius: Hemant Kumar Kassean (Réduit, Moka); Namibia: Pempelani Mufune (Windhoek); Nigeria: Solu Olowu (lle-Ife); Pakistan: Rehana Reman (Karachi); Philippines: Alice Ferrer (Miagao); Russia: Alexander Gasparishvili (Moscow); Singapore: Mee Lian Wong (Singapore); South Africa: Tholene Sodi 
(Polokwane); Thailand: Tawatchai Apidechkul (Chiang Rai); Tunisia: Hajer Aounallah-Skhiri (Tunis); Turkey: Neslihan Keser Özcan (Istanbul); Venezuela: Yajaira M Bastardo (Caracas).

\section{References}

Andresen, E. M., Malmgren, J. A., Carter, W. B., \& Patrick, D. L. (1994). Screening for depression in well older adults: evaluation of a short form of the CES-D (Center for Epidemiologic Studies Depression Scale). American Journal of Preventive Medicine, 10(2), 77-84.

Aertgeerts, B., \& Buntinx, F. (2002). The relation between alcohol abuse or dependence and academic performance in first-year college students. Journal of Adolescent Health, 31(3), 223-5.

Babor, T. F., Higgins-Biddle, J. C., Saunders, J. B., \& Monteiro, M. (2001). AUDIT: The Alcohol Use Disorder Identification Test. Geneva, Switzerland: World Health Organization.

Bradley, B. J., \& Greenem A. C. (2013). Do health and education agencies in the United States share responsibility for academic achievement and health? A review of 25 years of evidence about the relationship of adolescents' academic achievement and health behaviors. Journal of Adolescent Health, 52(6), 808.

Bretz, Jr., R.D. (1989). College grade point average as a predictor of adult success: a meta-analytic review and some additional evidence. Public Personnel Management, 18(1), 11-21.

Brock, D., Sarason, I., Sarason, B., \& Pierce, G. (1996). Simultaneous assessment of perceived global and relationship-specific support. Journal of Social and Personal Relationships, 13, 143-152.

Centers for Disease Control (CDC) (2013). The Global School and Health Survey background. Available from http://www.cdc.gov/gshs/background/index.htm at 15 April 2013.

Cogollo, Z., \& Gómez-Bustamante, E. M. (2013). Health risk behavior pattern among students from Cartagena, Colombia: prevalence and associated variables. Revista da Escola de Enfermagem da USP, 47(4), 830-5.

Craig, C. L., Marshall, A. L., Sjöström, M., Bauman, A. E., Booth, M. L., Ainsworth, B. E.,... Oja, P. (2003). International physical activity questionnaire: 12-Country reliability and validity. Medicine and Science in Sports and Exercise, 35, 1381-1395.

Deliens, T., Clarys, P., De Bourdeaudhuij, I., \& Deforche, B. (2013). Weight, socio-demographics, and health behaviour related correlates of academic performance in first year university students. Nutrition Journal,12, 162. doi: 10.1186/1475-2891-12-162.

El Ansari, W., \& Stock, C. (2010). Is the health and wellbeing of university students associated with their academic performance? Cross sectional findings from the United Kingdom. International Journal of Environmental Research and Public Health, 7(2), 509-27.

Eliasson, A. H., Lettieri, C. J., \& Eliasson, A. H. (2010). Early to bed, early to rise! Sleep habits and academic performance in college students. Sleep Breath, 14(1), 71-5.

Florence, M. D., Asbridge, M., \& Veugelers, P. J. (2008). Diet quality and academic performance. Journal of School Health,78(4), 20915.

Gajre, N. S., Fernandez, S., Balakrishna, N., \& Vazir, S. (2008). Breakfast eating habit and its influence on attention-concentration, immediate memory and school achievement. Indian Pediatrics, 45(10), 824-8.

Gomes, A. A., Tavares, J., \& de Azevedo, M. H. (2011). Sleep and academic performance in undergraduates: a multi-measure, multipredictor approach. Chronobiology International, 28(9), 786-801.

Hall, J. N., Moore, S., Harper, S.B., \& Lynch, J.W. (2009). Global variability in fruit and vegetable consumption. American Journal of Preventive Medicine, 36, 402-409.

Hublin, C., Partinen, M., Koskenvuo, M., \& Kaprio, J. (2007). Sleep and mortality: a population-based 22 year follow-up study. Sleep, 30, 1245-53.

International Physical Activity Questionnaire (IPAQ). IPAQ Scoring Protocol. Available online: https://sites.google.com/site/theipaq/ (accessed on 5 April 2014)

Keyes, C. L., Eisenberg, D., Perry, G. S., Dube, S. R., Kroenke, K., \& Dhingra, S. S. (2012). The relationship of level of positive mental health with current mental disorders in predicting suicidal behavior and academic impairment in college students. Journal of American College Health, 60(2), 126-33.

Kilbourne, A., Justice, A., Rollman, B., McGinnis, K., Rabeneck, L., Weissman, S., ... Rodriguez-Barradas, M. (2002). Clinical importance of HIV and depressive symptoms among veterans with HIV infection. Journal of General and Internal Medicine, 17(7), 512-520.

Kimerling, R., Ouimette, P., Prins, A., Nisco, P., Lawler, C., Cronkite, R., \& Moos, R. H. (2006). Brief report: Utility of a short screening scale for DSM-IV PTSD in primary care. Journal of General and Internal Medicine, 21, 65-67.

Koenig, H. G., Parkerson, G. R. Jr., \& Meador, K. G. (1997). Religion index for psychiatric research. American Journal of Psychiatry,154, 885-886.

Lees, C., \& Hopkins, J. (2013). Effect of aerobic exercise on cognition, academic achievement, and psychosocial function in children: a systematic review of randomized control trials. Preventing Chronic Disease, 10, E174. doi: 10.5888/pcd10.130010.

Malecki, C. K., \& Demaray, M. K. (2006). Social support as a buffer in the relationship between socioeconomic status and academic performance. School Psychology Quarterly, 21(4), 375-395.

Mehra, D., Kyagaba, E., Ostergren, P. O., \& Agardh, A. (2014). Association between self-reported academic performance and risky sexual behavior among Ugandan university students- a cross sectional study. Global Journal of Health Science, 6(4), 30889. doi: 10.5539/gjhs.v6n4p183. 
Richardson, M., Abraham, C., \& Bond, R. (2012). Psychological correlates of university students' academic performance: a systematic review and meta-analysis. Psychological Bulletin, 138(2), 353-87.

Singh, A., Uijtdewilligen, L., Twisk, J.W., van Mechelen, W., \& Chinapaw, M. J. (2012). Physical activity and performance at school: a systematic review of the literature including a methodological quality assessment. Archives of Pediatrics \& Adolescent Medicine, 166(1), 49-55.

Sirin, S. R. (2005). Socioeconomic status and academic achievement: a meta-analytic review of research. Review of Educational Research, 75(3), 417-453.

Springer, A., Parcel, G., Baumler, E., \& Ross, M. (2006). Supportive social relationships and adolescent health risk behavior among secondary school students in El Salvador. Social Science and Medicine, 62(7), 1628-40.

Steptoe, A., Peacey, V., \& Wardle, J. (2006). Sleep duration and health in young adults. Archives of Internal Medicine, 166, 1689-1692.

Stranges, S., Tigbe, W., Gómez-Olivé, F. X., Thorogood, M., \& Kandala, N. B. (2012). Sleep problems: an emerging global epidemic? Findings from the INDEPTH WHO-SAGE study among more than 40,000 older adults from 8 countries across Africa and Asia. Sleep, 35, 1173-1181.

Trockel, M. T., Barnes, M. D., \& Egget, D. L. (2000). Health-related variables and academic performance among first-year college students: implications for sleep and other behaviors. Journal of American College Health, 49(3), 125-31.

Turner, D. P., Thompson, M. E., Huber, L. R., \& Arif, A. A. (2012). Depressive symptoms and academic performance of North Carolina college students. North Carolina Medical Journal, 73(3), 169-75.

Vaez, M., \& Laflamme, L. (2008). Experienced stress, psychological symptoms, self-rated health and academic achievement: a longitudinal study of Swedish university students. Social Behavior and Personality, 36, 183-195.

Walker, K. L., \& Dixon, V. (2002). Spirituality and Academic Performance among African American College Students. Journal of Black Psychology, 28(2), 107-121.

Wald, A., Muennig, P. A., O'Connell, K. A., \& Garber, C. E. (2014). Associations between healthy lifestyle behaviors and academic performance in U.S. undergraduates: a secondary analysis of the American College Health Association's National College Health Assessment II. American Journal of Health Promotion, 28(5), 298-305.

Wardle, J., \& Steptoe, A. (1991). The European Health and Behaviour Survey: rationale, methods and initial results from the United Kingdom. Social Science and Medicine, 33, 925-36.

World Health Organization (WHO) (1998). Guidelines for controlling and monitoring the tobacco epidemic. Geneva, Switzerland: WHO. 